\title{
Personal Characteristics of Older Primary Care Patients Who Provide a Buccal Swab for Apolipoprotein E Testing and Banking of Genetic Material: The Spectrum Study
}

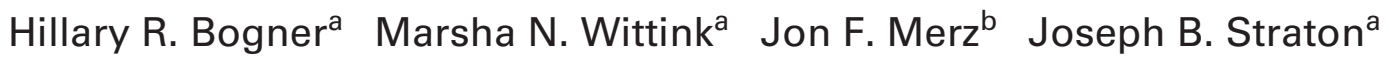 \\ Peter F. Cronholm ${ }^{a}$ Peter V. Rabins ${ }^{c}$ Joseph J. Gallo ${ }^{a}$ \\ ${ }^{a}$ Department of Family Practice and Community Medicine, and ${ }^{b}$ Center for Bioethics, University of Pennsylvania \\ School of Medicine, Philadelphia, Pa., and ' Department of Psychiatry, Johns Hopkins School of Medicine, \\ Baltimore, Md., USA
}

\section{Key Words}

Apolipoprotein E · Genetic testing • Older adults ·

Participant recruitment $\cdot$ Race

\begin{abstract}
Objective: To determine the personal characteristics and reasons associated with providing a buccal swab for apolipoprotein E (APOE) genetic testing in a primary care study. Methods: The study sample consisted of 342 adults aged 65 years and older recruited from primary care settings. Results: In all, $88 \%$ of patients agreed to provide a DNA sample for APOE genotyping and $78 \%$ of persons providing a sample agreed to banking of the DNA. Persons aged 80 years and older and AfricanAmericans were less likely to participate in APOE genotyping. Concern about confidentiality was the most common reason for not wanting to provide a DNA sample or to have DNA banked. Conclusion: We found stronger relationships between sociodemographic variables of age and ethnicity with participation in genetic testing than we did between level of educational attainment, gender, function, cognition, and affect.
\end{abstract}

Copyright $(C 2004$ S. Karger AG, Basel

\section{Introduction}

The Human Genome Project has significantly expanded our knowledge of genetic information. Translating these genetic discoveries into improved health outcomes requires integrating genetics into public health research. Translating research into practice involves research based on primary care practice since genetic testing is often first discussed in primary care settings. However, research involving genetics raises serious social and ethical concerns and considerations for patients. In order for research involving genetic testing to result in improved medical therapy, these concerns need to be understood and addressed [1]. An understanding of patients' concerns and perceptions about research involving genetics is an important step in the integration of genetic discoveries into medical practice.

Participation in genetic research is influenced both by the risks involved but also by the perceived magnitude of those risks by potential participants. Concerns about how private health information is shared with persons not involved in medical care of the individual have led to legislation (Health Insurance Portability and Accountability Act of 1996, Public Law 104-191 104th Congress). The

\section{KARGER \\ Fax +4161306 1234 E-Mailkarger@karger.ch} www.karger.com
Assist. Prof. Hillary R. Bogner, MD, MSCE

Department of Family Practice and Community Medicine

University of Pennsylvania, 3400 Spruce Street

2 Gates Building, Philadelphia, PA 19104 (USA)

Tel. +1 215615 0851, Fax +1 215662 3591, E-Mail bogner@mail.med.upenn.edu 
potential for misuse of personal medical information relates closely to employment and insurance eligibility [2]. Medical benefits have been denied to retired persons who have medical illnesses with a known genetic basis [3]. An individual's privacy also needs to be protected within the context of their family. Some genetic studies involve identifying gene mutations in families that might act as a predisposition to disease. Some family members may choose not to participate in these studies [4]. In addition, when genetic information is connected with specific groups of people, there is the potential for discrimination of individuals based on age, gender, ethnicity, as well as other personal characteristics. For example, the potential for discrimination of the elderly population in the United States is significant as the population ages and the costs of health care associated with aging increase [5]. However, little is known about how potential participants in genetic research perceive and weigh their risks and benefits associated with participation in a particular study. We know of no available data to date exploring participation preferences of older primary care patients concerning genetic testing for research purposes.

Previous studies not involving genetic testing have found that recruiting older adults into clinical research is difficult [6]. In most psychiatric studies of older adults there are significantly lower response rates compared to studies of younger samples [7]. As an illustration of the difficulty of recruiting and retaining older adults in antidepressant trials, consider the experience of Stevens et al. [8], who, after finding 55 older patients with depression identified from a community survey, only had 6 consent to the trial, and of those 6 , none completed the trial. Furthermore, the recruitment of older ethnic minority adults has been found to be even more challenging $[6,7]$. African-Americans, in particular, may not be enthusiastic about participation in research due to past exploitation from research studies [9]. To assure adequate representation from older adults and in particular older ethnic minority adults in research involving genetic tests, the concerns of potential participants need to be addressed.

Our goal was to investigate the reasons for nonparticipation in buccal swab apolipoprotein E (APOE) genotyping in a primary care study. Epidemiologic studies have found that the $\epsilon 4$ allele of APOE has been associated with an increased prevalence of cardiovascular disease and particularly of Alzheimer's disease [10, 11]. Our study was part of a larger project, the goal of which was to assess how APOE genotype and cognitive functioning assessed at baseline are related to the form and course of depressive symptoms and cognitive impairment in older primary care patients. Our investigation differs in several ways from other investigations exploring participant preferences for genetic testing. The sample derives from a large sample of older adults in the primary care setting. We are exploring patient preferences for participation in research initiatives as opposed to the issues and implications of clinical genetic testing. We have excellent measures of potential participants' cognitive, functional and psychological status which have not previously been studied in relation to participation in genetic research. In addition, our study respondents had already agreed to participate in a larger research study so here we are examining specifically the reasons for nonparticipation in the aspect of the research involving genetic testing. In other words, persons who refused to provide a genetic sample or to allow their sample to be banked had already participated in a research study of depression and health involving an interview in their homes, so any refusal here was specific to genetic testing.

Our conceptual model incorporated cultural influences as well as mental and physical health states in characterizing patient preferences for participation in genetic testing. We hypothesized that patients who were older $[12,13]$, African-American [6, 7, 12], depressed [8], anxious, or cognitively or functionally impaired [7] would be less likely than others to participate. We included anxiety, and cognitive and functional impairment in our conceptual model, because we hypothesized they might be markers for people who have limited ability to process information. In addition, we postulated that the most common reasons older primary care patients would refuse genetic testing would be concern about confidentiality and privacy.

\section{Material and Methods}

\section{The Spectrum Survey}

The Spectrum Survey is an observational study designed to describe and validate a depressive syndrome, apathetic depression, which does not meet standard criteria for major depression in older primary care patients. Primary care practices recruited from the community provided the venue for sampling older patients. Trained lay interviewers were instructed in screening and study interviews by the study investigators working with the Centers for Public Health Research and Evaluation of the Battelle Memorial Institute, Baltimore, Md., USA. Participants who agreed to be part of the study were scheduled for an in-home interview which consisted of a 90-min survey questionnaire use of a buccal swab to obtain a sample for APOE genotyping. In all, 3,459 patients aged 65 years and older were approached and 2,560 participated in the screening questionnaire (74\% participation rate). The eligible sample was $30 \%$ African-American, which was not significantly different from 
$33 \%$ in the recruited sample $(\mathrm{p}=0.51)$. In contrast, persons aged 80 years and older were less likely to participate in the in-home interview ( $33 \%$ of the eligible sample was 80 years and older while $24 \%$ of the recruited sample was 80 years and older). Implications of having proportionally fewer persons aged 80 years and older in the final sample will be considered in our discussion of results. Inhome interviews were obtained for 357 people, but 2 persons broke off the interview before it was completed, leaving a sample of 355 persons. The study protocols were approved by the Institutional Review Board of the University of Pennsylvania School of Medicine. A federal Certificate of Confidentiality was obtained from the Department of Health and Human Services as an additional confidentiality safeguard for survey and genetic data. A Certificate of Confidentiality protects the study data from subpoena.

\section{Consent Procedure for Providing a Buccal Swab}

Participants were told that providing an interview did not mean they needed to provide a buccal swab. A consent form separate from the consent form for the interviews explained the genotyping procedure and the purpose of the biological samples. Interviewers were trained to anticipate and answer questions about the genotyping procedure. Participants were allowed to choose on the consent form whether they would participate in APOE genotyping only or whether they would participate in APOE genotyping as well as allow their DNA to be banked for future studies involving mental health. Participants were told they and their doctors would not be given the results of the genetic testing.

Participants who refused the buccal swab procedure were asked the reasons they chose not to participate. They were asked the following open-ended question: 'I understand that you do not want genetic testing to be done. I respect your decision. The doctors are trying to understand why people do not choose to participate in this part of the survey. Please tell me why you do not want the swab to be taken.' Next the interviewer was trained to probe for concerns about 'the swab procedure', 'confidentiality', 'ability to be insured', 'ability to be employed', 'cloning', 'effect on family member', or for any other reason. The interviewer was asked to indicate all responses that applied, and to record any reasons given by the respondent that did not fit into the specific categories.

The participants who agreed to the buccal swab for APOE genotyping but refused to have their DNA banked were asked the following open-ended question: 'I understand that you do not want the storage of your DNA to be done. I respect your decision. The doctors are trying to understand why people do not choose to participate in this part of the survey. Please tell me why you do not want your DNA stored.' Next the interviewer was trained to probe for concern about 'confidentiality', 'ability to be insured', 'ability to be employed', 'cloning', 'effect on family member', or for any other reason. Again, the interviewer was asked to indicate all responses that applied, and to record other answers verbatim.

\section{Measurement Strategy}

We used standard questions to obtain information from the respondents on age, gender, self-reported ethnicity, and education. The Mini-Mental State Examination (MMSE) is a short standardized mental status examination that has been widely employed for clinical and research purposes [14]. The MMSE has been extensively studied, as reviewed by Tombaugh and McIntyre [15] and by Crum et al. [16]. The Controlled Oral Word Association Test (FAS) serves as a test of verbal production and access to semantic knowl- edge and language [17]. The respondent is asked to generate as many words as possible that begin with a certain letter in $1 \mathrm{~min}$. Participants were asked to generate words for the letters $\mathrm{F}, \mathrm{A}$, and $\mathrm{S}$. The score is the sum of all correct words produced in the three 1-min trials. For letters, reported inter-rater reliability was near perfect, 1-year re-test reliability was 0.70 [18] and short-term reliability (1942 days) was 0.88 [19]. The Hopkins Verbal Learning Task evaluates new verbal learning and memory. On each of three trials, in this study, participants listened to 12 words ( 4 from each of 3 different semantic categories), read at 2-second intervals, and were asked to recall as many of the words as possible [20]. For the present investigation, we employed the total number of words correctly recalled over all three trials. The Brief Test of Attention is a short test of auditory selective attention [21]. In our study, a series of numbers and letters were read. Respondents were required to report the number of letters presented. The number of digits and letters in the series increases from 4 to 18 over the course of 10 trials. A score of the number of trials correctly completed was recorded. The Medical Outcomes Study Short Form (SF-36) has been employed in studies of outcomes of patient care [22-26] and appears to be reliable and valid even in frail elders [27]. We employed the scales representing physical functioning, role disability due to physical health problems, bodily pain, general health perceptions, social functioning, and role disability due to emotional problems [23]. The SF-36 was scored using previously described techniques [28]. The scale for each dimension ranges from 0 to 100, with higher numbers representing better health. The Centers for Epidemiologic Studies Depression (CES-D) scale was developed by the Center for Epidemiologic Studies at the National Institute of Mental Health for use in studies of depression in community samples [29-31]. The CESD contains 20 items. Consistent with other studies, a threshold of 17 and above is taken as defining 'caseness' [32]. The CES-D has been employed in studies of older adults $[33,34]$. The Beck Anxiety Inventory (BAI) was developed in order to measure the severity of anxiety symptoms [35]. The BAI is a 21-item, self-report instrument designed to minimize the relationship of symptoms of anxiety and depressive symptoms. Total scores range from 0 to 63 . Steer et al. [36] suggest that scores of 15 or greater represent moderate to severe levels of anxiety. Designed to avoid confounding with depression, the BAI has been shown to be an appropriate instrument for measuring symptoms of anxiety in the elderly [37].

\section{Analytic Strategy}

Data analysis was performed using SPSS version 10 . The analytic plan proceeded in three phases. The first phase consisted of calculating descriptive statistics for the participants who agreed to APOE genotyping and the characteristics of persons who agreed to APOE genotyping and DNA banking. Comparisons between groups of participants were made using $\chi^{2}$ tests or $t$ tests as appropriate for categorical data or differences in means. We set $\alpha$ at 0.05 recognizing that tests of statistical significance are approximations that serve as aids to interpretation and inference. Our study sample included 342 persons who had completed a baseline in-home interview as well as had complete information on providing a buccal swab. The second phase consisted of carrying out multivariate analyses to examine the characteristics of the persons who agreed to APOE genotyping and the characteristics of persons who agreed to APOE genotyping and DNA banking. Our measure of association was the odds ratio. We employed separate multivariate logistic regression models to assess the relationship of age to agreeing to the 
Table 1. Characteristics of older persons who provided genetic material and allowed banking of the DNA $(n=342)$

\begin{tabular}{|c|c|c|c|c|}
\hline Characteristics & $\begin{array}{l}\text { Allowed geno- } \\
\text { typing and } \\
\text { banking of DNA } \\
(\mathrm{n}=234)\end{array}$ & $\begin{array}{l}\text { Allowed geno- } \\
\text { typing but not } \\
\text { banking of DNA } \\
(\mathrm{n}=67)\end{array}$ & $\begin{array}{l}\text { Did not allow } \\
\text { genotyping or } \\
\text { banking of DNA } \\
(\mathrm{n}=41)\end{array}$ & $\begin{array}{l}\chi^{2} \\
\mathrm{p} \text { value }\end{array}$ \\
\hline \multicolumn{5}{|l|}{ Demographics } \\
\hline Age: 80 and older $(n=79)$ & $(\mathrm{n}=39) 49.4 \%$ & $(\mathrm{n}=25) 31.6 \%$ & $(\mathrm{n}=15) 19.0 \%$ & $\mathrm{p}=0.001^{*}$ \\
\hline Gender: female $(\mathrm{n}=259)$ & $(\mathrm{n}=181) 69.9 \%$ & $(n=47) 18.1 \%$ & $(\mathrm{n}=31) 12.0 \%$ & $\mathrm{p}=0.480$ \\
\hline \multicolumn{5}{|l|}{ Education, did not graduate } \\
\hline high school $(n=141)$ & $(\mathrm{n}=98) 69.5 \%$ & $(\mathrm{n}=28) 19.9 \%$ & $(\mathrm{n}=15) 10.6 \%$ & $\mathrm{p}=0.813$ \\
\hline Ethnicity, black $(\mathrm{n}=118)$ & $(\mathrm{n}=81) 68.6 \%$ & $(\mathrm{n}=12) 10.2 \%$ & $(\mathrm{n}=19) 16.1 \%$ & $\mathrm{p}=0.005^{*}$ \\
\hline \multicolumn{5}{|l|}{ Functional status, mean (SD) } \\
\hline Physical functioning & $57.4(29.5)$ & $61.8(27.9)$ & $57.8(28.7)$ & $\mathrm{p}=0.549$ \\
\hline Role physical & $43.1(39.5)$ & $47.6(40.9)$ & $34.8(38.3)$ & $\mathrm{p}=0.262$ \\
\hline Role emotional & $76.1(38.6)$ & $66.2(40.4)$ & $73.2(41.0)$ & $\mathrm{p}=0.186$ \\
\hline Social function & $70.2(28.1)$ & $74.8(26.8)$ & $70.7(27.0)$ & $\mathrm{p}=0.491$ \\
\hline Bodily pain & $53.0(24.2)$ & $57.7(26.0)$ & $54.7(24.0)$ & $\mathrm{p}=0.373$ \\
\hline General health perception & $49.5(20.2)$ & $53.4(20.8)$ & $52.7(20.7)$ & $\mathrm{p}=0.314$ \\
\hline \multicolumn{5}{|l|}{ Cognitive status, mean (SD) } \\
\hline MMSE & $27.1(2.9)$ & $26.7(2.6)$ & $26.9(2.3)$ & $\mathrm{p}=0.490$ \\
\hline FAS & $27.43(12.9)$ & $23.70(10.9)$ & $26.36(12.9)$ & $\mathrm{p}=0.104$ \\
\hline HVLT & $18.22(6.2)$ & $17.40(5.9)$ & $17.59(6.0)$ & $\mathrm{p}=0.573$ \\
\hline Attention task & $5.54(2.5)$ & $5.40(2.7)$ & $5.15(2.6)$ & $\mathrm{p}=0.642$ \\
\hline \multicolumn{5}{|c|}{ Psychological status, mean (SD) } \\
\hline Beck anxiety & $9.1(8.3)$ & $9.8(9.2)$ & $8.1(6.6)$ & $\mathrm{p}=0.568$ \\
\hline CESD & $14.9(11.3)$ & $14.4(12.7)$ & $14.5(8.8)$ & $\mathrm{p}=0.939$ \\
\hline
\end{tabular}

APOE genotyping and agreeing to APOE genotyping and DNA banking. These multivariate models were adjusted for gender, education, ethnicity, SF-36, MMSE, CES-D, and BAI. We also employed separate multivariate logistic regression models to assess the relationship of ethnicity to agreeing to the APOE genotyping and agreeing to APOE genotyping and DNA banking. Multivariate models were adjusted for age, gender, education, SF-36, MMSE, CES-D, and BAI. Goodness-of-fit was assessed for all final multivariate models using the Hosmer-Lemeshow test [38]. The third phase consisted of examining the reasons people gave for not participating in APOE genotyping or for not permitting DNA banking. Twenty-eight persons were excluded from this part of the analysis because complete information was not available on the reasons participants did not agree to APOE genotyping, leaving a sample size of 314 for this part of the analysis.

\section{Results}

\section{Study Sample}

The mean age of our study sample was 75.2 years with a standard deviation of 5.93 years. The age range was 65-92 years. Two hundred and fifty-nine $(75.7 \%)$ of the participants were women. One hundred and twelve (32.7\%) of the participants self-identified themselves as African-American. Of all the 342 participants, 301 (88.0\%) agreed to provide a DNA sample and $234(77.7 \%)$ of those agreed to banking of the DNA.

\section{Characteristics Associated with Providing a Sample and Banking of DNA}

Sociodemographic characteristics, cognitive and functional status, and psychological status were compared among persons who allowed genotyping and banking of DNA, who allowed genotyping but not banking of DNA, and who did not allow genotyping or banking of DNA (table 1). Respondents who did not agree to provide a buccal swab for APOE genotyping were more likely to be age 80 and older and African-American. Participants who were age 80 and older who provided a buccal swab were less likely to agree to the banking of DNA. However, African-Americans who provided a buccal swab were more likely to agree to the banking of DNA than were whites 
Table 2. Association between age and ethnicity and participation in APOE genotyping and banking of DNA $(\mathrm{n}=342)$

\begin{tabular}{|c|c|c|c|c|}
\hline \multirow[t]{2}{*}{$\begin{array}{l}\text { Personal } \\
\text { characteristics }\end{array}$} & \multicolumn{2}{|c|}{ Allowed APOE genotyping } & \multicolumn{2}{|c|}{$\begin{array}{l}\text { Allowed genotyping and } \\
\text { banking of DNA }\end{array}$} \\
\hline & $\begin{array}{l}\text { unadjusted OR } \\
(95 \% \mathrm{CI})\end{array}$ & $\begin{array}{l}\text { adjusted OR } \\
(95 \% \mathrm{CI})\end{array}$ & $\begin{array}{l}\text { unadjusted OR } \\
(95 \% \mathrm{CI})\end{array}$ & $\begin{array}{l}\text { adjusted OR } \\
(95 \% \mathrm{CI})\end{array}$ \\
\hline $\begin{array}{l}\text { Age } 80 \text { and older } \\
\text { (reference: <80) }\end{array}$ & $\begin{array}{l}0.47 \\
(0.23-0.94)\end{array}$ & $\begin{array}{l}0.42 \\
(0.20-0.87)^{1}\end{array}$ & $\begin{array}{l}0.34 \\
(0.18-0.61)\end{array}$ & $\begin{array}{l}0.36 \\
(0.19-0.68)^{1}\end{array}$ \\
\hline $\begin{array}{l}\text { African-American } \\
\quad \text { (reference: white) }\end{array}$ & $\begin{array}{l}0.52 \\
(0.27-1.00)\end{array}$ & $\begin{array}{l}0.43 \\
(0.20-0.89)^{2}\end{array}$ & $\begin{array}{l}2.43 \\
(1.23-4.79)\end{array}$ & $\begin{array}{l}2.31 \\
(1.10-4.89)^{2}\end{array}$ \\
\hline \multicolumn{5}{|c|}{$\begin{array}{l}\text { Data were gathered from the Spectrum Survey, 2001-2003. } \\
{ }^{1} \text { Adjusted for gender, education, ethnicity, SF-36, MMSE, CES-D, and BAI. } \\
{ }^{2} \text { Adjusted for age, gender, education, SF-36, MMSE, CES-D, and BAI. } \\
\text { OR = Odds ratio; CI = confidence interval. }\end{array}$} \\
\hline
\end{tabular}

Table 3. Reasons given for nonparticipation in APOE genotyping $(\mathrm{n}=27)$

\begin{tabular}{llc}
\hline Reasons given for nonparticipation & Persons & $\begin{array}{c}\text { Persons who did not } \\
\text { participate in APOE } \\
\text { genotyping, \% }\end{array}$ \\
\hline Swab procedure & 0 & 0 \\
Confidentiality & 6 & 22.2 \\
Ability to be insured & 0 & 0 \\
Cloning & 1 & 3.7 \\
Effect on a family member & 0 & 0 \\
Other & & \\
$\quad$ Nothing to gain/not interested & 7 & 25.9 \\
$\quad$ Doesn't feel well & 4 & 14.8 \\
$\quad$ Not comfortable/afraid what & & \\
$\quad$ will happen & 4 & 14.8 \\
Refused to give a reason & 2 & 7.4 \\
Don't know & 3 & 11.1 \\
\hline
\end{tabular}

Data were gathered from the Spectrum Survey, 2001-2003.

who provided a buccal swab. There was no difference in the mean length of the interview between participants who agreed and participants who did not agree to provide a sample. No significant differences were found between groups according to gender or education or in terms of education, functional, cognitive, or psychological status.

The associations between age, ethnicity, and other personal characteristics and participation in APOE genotyping and banking of DNA were further explored in multivariate analyses to assess whether other characteristics might explain the association of age and ethnicity with participation (table 2). Persons aged 80 and older were less likely to participate in APOE genotyping (odds ratio, $\mathrm{OR}=0.47,95 \%$ confidence interval, $\mathrm{CI}=0.23-0.94)$. The finding remained significant even after adjusting for gender, education, ethnicity, SF-36, MMSE, CES-D, and BAI (adjusted OR $=0.42,95 \% \mathrm{CI}=0.20-0.87$ ). Persons aged 80 and older were also less likely to participate in DNA banking $(\mathrm{OR}=0.34,95 \% \mathrm{CI}=0.18-0.61)$. There was no change in the estimate of association after adjustment (adjusted OR $=0.36,95 \% \mathrm{CI}=0.19-0.68$ ).

African-Americans were not significantly less likely to participate in APOE genotyping (unadjusted $\mathrm{OR}=0.52$, $95 \% \mathrm{CI}=0.27-1.00)$. However, the point estimate was significantly different from the null in the final model that included terms for age, gender, education, SF-36, MMSE, CES-D, and BAI (adjusted OR $=0.43,95 \%$ CI $=0.20$ 0.89 ). Once a DNA sample was provided, however, African-American patients were more likely than whites to permit their DNA to be banked $(\mathrm{OR}=2.43,95 \% \mathrm{CI}=$ 1.23-4.79). The point estimate remained unchanged with adjustment (adjusted $\mathrm{OR}=2.31,95 \% \mathrm{CI}=1.10-4.89$ ). $\mathrm{A}$ goodness-of-fit diagnostic and plots of the deviance residuals versus fitted values predicted by all final models showed that the coefficient estimates were not influenced appreciably by any one observation.

\section{Reasons Given for Not Providing a DNA Sample}

The reasons the participants gave for not providing a buccal swab for APOE genotyping are summarized in table 3. All the participants gave a single reason for not participating in the APOE genotyping although they were encouraged to give all the reasons that applied. The participants gave a variety of reasons for not wanting to provide a DNA sample but the most common reasons were concern about confidentiality and that the person felt they had nothing to gain or were not interested in participating. 
Table 4. Reasons given for nonparticipation in DNA banking $(\mathrm{n}=$ 43)

\begin{tabular}{lrl}
\hline Reasons given for nonparticipation & Persons & $\begin{array}{l}\text { Persons who did not } \\
\text { participate in DNA } \\
\text { banking, \% }\end{array}$ \\
\hline Confidentiality & 28 & 65.1 \\
Ability to be insured & 1 & 2.3 \\
Cloning & 1 & 2.3 \\
Effect on a family member & 0 & 0 \\
Other & 12 & 27.9 \\
$\quad$ Concern over the unknown & 3 & 7.0 \\
$\quad$ No good reason to store DNA & 2 & 4.7 \\
$\quad$ Privacy & 1 & 2.3 \\
Refused to give reason & 4 & 9.3 \\
Don't know & \\
\hline
\end{tabular}

Nine participants gave two responses. Data were gathered from the Spectrum Survey, 2001-2003.

\section{Reasons Given for Not Permitting the DNA to Be}

\section{Banked for Future Research}

The reasons the participants gave for not permitting their DNA to be banked for future research on aging and mental health are summarized in table 4 . Nine participants gave two reasons for not participating in the banking of DNA while the rest of the participants gave a single reason. The most common reason was confidentiality, but many potential participants reported concern over the unknown.

\section{Discussion}

In this large sample of older primary care patients, patients 80 years and older and African-Americans were less likely to provide a buccal swab than other older patients. Our results were not wholly consistent with our initial hypotheses. We did not find that depression, anxiety, or cognitive or functional impairment were strongly related to participation in genetic research in this sample. However, the association we found between age, ethnicity, and participation in genetic research was consistent with other studies that have shown similar associations in clinical research not involving genetic testing $[6,7,9]$. The main reason persons in our study chose not to participate in APOE genetic testing for research purposes as well as DNA banking was related to confidentiality despite assurances made in the consent process. This finding was consistent with other research concerning genetic testing for clinical purposes not involving research purposes that have consisted of mainly younger samples [39, 40]. Unlike other studies, our investigation focused on genetic testing of older adults in the context of a research project. Older adults described here had participated in an interview but specifically refused to participate in the genetic aspects of the study.

Before discussing our findings in further detail, the results must first be considered in the context of some potential study limitations. First, we obtained our results only from primary care sites in Maryland whose patients may not be representative of most primary care practices. However, these practices were not academically affiliated and are probably similar to other practices in the country. Second, selection bias is a potential limitation because, although the larger project was based on a random sample of primary care patients, the data on participation for APOE testing consisted of all the people who were selected for the larger project, agreed to participate, and had complete information on the reasons participants did not agree to APOE genotyping. Special efforts may be required to elicit participation of the oldest old who were less likely to participate in the main study as in the genetic component. Third, our findings and consent process would have been different if we had been studying one of the deterministic genes for a disease.

Nonetheless, despite limitations our results deserve attention because we attempted to characterize the reasons older primary care patients declined to participate in genetic research. In addition, because we examined a large group of older white and African-American primary care patients in non-academically affiliated practices, our results are potentially more generalizable to other older primary care patients. The study provides additional evidence of the concerns older primary care patients report when considering whether to participate in genetic research. The findings are important because we need to understand factors related to participation in research in genetics if we are to carry out community-based studies of genetics.

The first aim of this study was to examine the personal characteristics associated with providing a buccal swab for APOE genotyping and agreeing to DNA banking. Our study demonstrated that persons aged 80 and older were less likely to provide a buccal swab and those who provided a buccal swab were less likely to agree to DNA banking. Our data are consistent with Stevens et al. [8] who documented the difficulty of recruiting older adults into clinical trials as well as other studies demonstrating low participation rates among older adults $[12,13]$. The 
association of age and participation appeared to be independent of other characteristics that were studied, e.g. physical functioning, cognition, and affect.

The findings regarding African-American participation deserve special mention. These findings are specific to genetic testing, because African-American patients recruited from primary care practices were no less likely than white patients to participate in the parent study. The relationship between ethnicity and participation in APOE genotyping and DNA banking did not appear to be straightforward. Older African-Americans were less likely to provide a buccal swab than older whites, however, those who provided a buccal swab were more likely to agree to DNA banking. We wish to provide some context for understanding these findings. African-Americans are often skeptical about participating in research due to past abuse [9]. Two other issues to consider in recruitment of older ethnic minority adults are ethnocultural beliefs about illness and socioeconomic factors associated with being older and being part of an ethnic minority group. A number of articles have discussed all the issues related to recruiting older ethnic minority adults and AfricanAmericans into research $[6,7,12]$. One article specifically examined attitudes toward genetic testing for Alzheimer's disease and found African Americans showed less interest in testing than whites [41]. The reasons for the findings in our study are not entirely clear but might be related to an overall distrust of research due to past exploitation, but once that fear and distrust is overcome African-Americans will participate in the entire project if informed and given the opportunity to do so [42]. Our findings with respect to ethnicity reflect the preferences of persons who already agreed to take part in the parent study, and therefore the present investigation sharpens the focus that older ethnic minorities may be reluctant to participate in genetic studies in the community.

The second aim of our paper was to focus on the reasons older adults did not participate in genetic research. Although our study was derived from clinical settings, the genetic testing was focused on research. Studies with a clinical focus examining participation in genetic testing have found apprehension concerning genetic testing. One study offering carrier testing to siblings of patients with cystic fibrosis found that a significant number of participants were not interested in testing. The conclusion was drawn that being unaware of one's carrier status might be of psychological benefit to persons at high risk [40]. Another study offering cystic fibrosis testing to pregnant women found that the more knowledgeable women were about the disease the less likely they were to undergo car- rier screening thus avoiding difficult prenatal issues such as pregnancy termination [39]. The decision to undergo genetic testing appears to be related to whether the test is for personal or research purposes. One recent study offered the results of genetic testing from a research study to family members who were at risk for hereditary nonpolyposis colon cancer but $60 \%$ of the participants did not want to receive the results [43].

Our results demonstrate that older adults were particularly apprehensive about DNA banking. In particular older adults cited confidentiality and privacy as the main concerns. Clearly, stored genetic material has the potential to provide provocative information to further elucidate information about diseases. However, genetic material can also contain sensitive information that has the risk of placing individuals in a situation where they or their family may become stigmatized or discriminated against. In order to address issues of confidentiality and privacy, several recommendations have been made for obtaining appropriate consent to use human tissue for research purposes. The Centers for Disease Control and Prevention has formed an ad hoc multidisciplinary group to create an informed consent approach for integrating genetic variation into population-based research and the National Bioethics Advisory Commission has published an ethical policy guideline on research involving human biological materials [44, 45].

Our findings are relevant to an on-going debate of whether or not consent can be waived for previously stored human tissue. In the past, research involving archived human tissue in research has occasionally been permitted to proceed without consenting participants. Currently under US regulations, consent may be waived if an Institutional Review Board finds and documents that (1) there is minimal risk to the participant; (2) the rights or welfare of the participant will not be adversely affected, and (3) research would be impracticable without the waiver [46]. Much of the debate has evolved around the issue of minimal risk and subject identifiability [47]. Nonetheless, there is an unstated assumption underlying the ethical waiver of consent: that subjects, if asked, would likely consent to participation [48]. The argument has been made that consent for emergency research is unnecessary in light of data that show that nearly all participants in emergency studies who were asked afterwards acceded to their enrollment $[49,50]$. Similarly, consent for use of medical records in research has been thought to be unnecessary in light of a study at the Mayo Clinic that found that only a small fraction of patients contacted after the fact would not have consented [51, 52]. Our re- 
sults suggest however that a large proportion of solicited participants will refuse banking when asked. This finding implies that waiver of consent for banking of genetic samples may be unacceptable, and deserves further study.

Our study suggests ways for researchers to address the concerns of potential participants. A clear consent form is needed that addresses the purpose of the survey and the biological samples. Many people have a very limited understanding of genetics and a brief example of how genetic material is used in research might even be helpful. The consent form should clearly spell out what is being asked of participants and what will happen to the specimens and the information provided. In addition, allowing participants to select how their tissues will be used on the consent form has the advantage of allowing participants to be explicit about what they want. Separating consent for genetic research from consent for the main study may help foster trust between the researcher and participants and may enhance the participation of persons who only want minimal involvement. Allowing participants to check a box to indicate how their tissues will be used on the consent form is the format recommended by the National Heart, Lung and Blood Institute [53]. Researchers also have the option of obtaining a federal Certificate of Confidentiality which protects federally and privately funded institutions from being compelled to reveal information about research participants [54].

Research continues to be needed to help define the best protocols by which to conduct genetic research. Our survey study which incorporated a genetic component demonstrated that personal factors affect participation in genetic research, and improved methods are needed for recruiting older adults and ethnic minorities into genetic research. Characteristics such as depression, anxiety, or cognitive or functional impairment were not strongly related to participation. We were able to obtain information on how potential participants perceive the risks of participation in genetic research, and confidentiality was an important concern. Measures that can be taken to address confidentiality and privacy issues inherent to genetic research are extremely important and include obtaining a federal Certificate of Confidentiality. In addition, we found that participants had explicit ideas about what they wanted to be done with their DNA and an informed consent form which allowed them to choose among different options was very important. Genetic research can add to survey studies to address many questions important to improving the detection and treatment of medical illness.

\section{Acknowledgments}

This study was presented in part at the Annual Meeting of the American Association for Geriatric Psychiatry, Orlando, Fla., USA, February 2002. The Spectrum Study was supported by grants MH62210-01, MH62210-01S1, and MH67077 from the National Institute of Mental Health. H.R.B. was supported by a NIMH Mentored Patient-Oriented Research Career Development Award (MH67671-01). The investigators gratefully acknowledge the patients who participated; the assistance of the Maryland Academy of Family Physicians, Baltimore, Md., USA (Esther Barr, Executive Director); physicians and office staffs of the participating practices (a list of participating practices can be found at www.uphs.upenn. edu/spectrum), and, the interviewers and supervising staff of the Centers for Public Health Research of the Battelle Memorial Institute, Baltimore, Maryland (Pat Lesho, Project Manager). A list of members of the Spectrum Study work groups can be found at the web site.

\section{References}

1 Schimpf MO, Domino SE: Implications of the Human Genome Project for obstetrics and gynecology. Obstet Gynecol Surv 2001;56:437443.

2 Geller G, Botkin JR, Green MJ, et al: Genetic testing for susceptibility to adult-onset cancer. The process and content of informed consent. JAMA 1996;277:1467-1474.

3 Fuller BP, Kahn MJE, Barr PA, et al: Privacy in genetics research. Science 1999;285:13591361.

4 Green RM, Thomas AM: Whose gene is it? A case discussion about familial conflict over genetic testing for breast cancer. J Genet Couns 1997;6:245-254.
5 National Research Council: Cells and Surveys: Should Biological Measures Be Included in Social Science Research? Washington, National Academy Press, 2000.

-6 Ballard EL, Nash F, Raiford K, Harrell LE: Recruitment of Black elderly for clinical research studies of dementia: The CERAD experience. Gerontologist 1993;33:561-565.

7 Carter WB, Elward K, Malmgren J, Martin ML, Larson E: Participation of older adults in health programs and research: A critical review of the literature. Gerontologist 1991;33:584592.
8 Stevens T, Katona C, Manela M, Watkin V, Livingston G: Drug treatment of older people with affective disorders in the community: Lessons from an attempted clinical trial. Int $\mathbf{J}$ Geriatr Psychiatry 1999;14:467-472.

-9 Shavers-Hornaday VL, Lynch CF, Burmeister LF, Torner JC: Why are African Americans under-represented in medical research studies? Impediments to participation. Ethn Health 1997;2:31-45.

10 Smith JD: Apolipoprotein $\epsilon 4$ : An allele associated with many diseases. Ann Med 2000;32: 118-127. 
$\checkmark 11$ Khachaturian AS, Corcoran CD, Mayer LS, Zandi PP, Breitner JC: Apolipoprotein E $\epsilon 4$ count affects age at onset of Alzheimer's disease, but not lifetime susceptibility: The Cache County study. Arch Gen Psychiatry 2004;61: 518-524.

12 Arean PA, Gallagher-Thompson D: Issues and recommendations for the recruitment and retention of older ethnic minority adults into clinical research. J Consult Clin Psychol 1996; 64:875-880.

13 Brown DR, Topcu M: Willingness to participate in clinical treatment research among older African Americans and whites. Gerontologist 2003;43:62-72.

14 Folstein MF, Folstein SE, McHugh PR: 'MiniMental State': A practical method for grading the cognitive state of patients for the clinician. J Psychiatr Res 1975;12:189-198.

15 Tombaugh TN, McIntyre NJ: The Mini-Mental State Examination: A comprehensive review. J Am Geriatr Soc 1992;40:922-935.

-16 Crum RM, Anthony JC, Bassett SS, Folstein MF: Population-based norms for the MiniMental State Examination by age and educational level. JAMA 1993;269:2386-2391.

17 Benton AL, Hamsher K: Multilingual Aphasia Examination. Iowa City, AJA Associates, 1983.

18 Snow WG, Tierney MC, Zorzitto ML: One year test-retest reliability of selected neuropsychological tests in older adults (abstract). J Clin Exp Neuropsychol 1988;10:60.

19 desRosiers G, Kavanagh D: Cognitive assessment in closed head injury: Stability, validity, and parallel form for two neuropsychological measures of recovery. Int J Clin Neuropsychol 1987;9:162-173.

20 Brandt J: The Hopkins Verbal Learning Test: Development of a new memory test with six equivalent forms. Clin Neuropsychol 1991;5: 125-142.

21 Schretlen D, Bobholz JM, Brandt J: Development and psychometric properties of the Brief Test of Attention. Baltimore, Clin Neuropsychol 1996;10:8089.

-22 Stewart AL, Greenfield S, Hays RD, et al: Functional status and well-being of patients with chronic conditions: Results from the Medical Outcomes Study. JAMA 1989;262: 907-913.

23 Stewart AL, Ware JE (eds): Measuring Functioning and Well-Being. Durham, Duke University Press, 1993.

24 Stewart AL, Hays RD, Ware JE: The MOS Short-form General Health Survey: Reliability and validity in a patient population. Med Care 1988;26:724-735.
25 Wells KB, Stewart A, Hays RD, et al: The functioning and well-being of depressed patients: Results from the Medical Outcomes Study. JAMA 1989;262:914-919.

26 McHorney CA: Measuring and monitoring general health status in elderly persons: Practical and methodological issues in using the SF36 health survey. Gerontologist 1996;36:571583.

27 Stadnyk K, Calder J, Rockwood K: Testing the measurement properties of the Short Form-36 health survey in a frail elderly population. $\mathrm{J}$ Clin Epidemiol 1998;51:827-835.

28 International Resource Center for Health Assessment: How to Score the MOS 36-Item (Short Form Health Survey SF-36). Boston, New England Medical Center, 1991.

29 Comstock GW, Helsing KJ: Symptoms of depression in two communities. Psychol Med 1976;6:551-563.

30 Eaton WW, Kessler LG: Rates of symptoms of depression in a national sample. Am J Epidemiol 1981;114:528-538.

31 Radloff LS: The CES-D Scale: A self-report depression scale for research in the general population. Appl Psychol Meas 1977;1:385-401.

32 Katon W, Schulberg HC: Epidemiology of depression in primary care. Gen Hosp Psychiatry 1992;14:237-247.

33 Newmann JP, Engel RJ, Jensen J: Age differences in depressive symptom experiences. $\mathrm{J}$ Gerontol 1991;46:224-235.

34 Gatz M, Johansson B, Pedersen N, Berg S, Reynolds C: A cross-national self-report measure of depressive symptomatology. Int Psychogeriatr 1993;5:147-156.

-35 Beck AT, Epstein N, Brown G, Steer RA: An inventory for measuring clinical anxiety: Psychometric properties. J Consult Clin Psychol 1988;56:893-897.

36 Steer RA, Ranieri WF, Beck AT, Clark DA: Further evidence for the validity of the Beck Anxiety Inventory with psychiatric outpatients. J Anxiety Disord 1993; 7:195-205.

37 Steer RA, Willman M, Kay PAJ, Beck AT: Differentiating elderly medical and psychiatric outpatients with the Beck Anxiety Inventory. Assessment 1994;1:345-351.

38 Hosmer DW, Lemeshow S: Applied Logistic Regression. New York, Wiley, 1989.

- 39 Botkin JR, Alemagno S: Carrier screening for cystic fibrosis: A pilot study of the attitudes of pregnant women. Am J Publ Health 1991;82: 723-725.

40 Fanos JH, Johnson JP: Barriers to carrier testing for adult cystic fibrosis sibs: The importance of not knowing. Am J Med Genet 1995; 59:85-91.

-41 Hipps YG, Roberts JS, Farrer LA, Green RC: Differences between African Americans and Whites in their attitudes toward genetic testing for Alzheimer's disease. Genet Test 2003;7: $39-44$.
42 Lee MM, Chamberlain RM, Catchatourian R, Hiang J, Kopnick M, Ray P, Vijayakumar S: Social factors affecting interest in participating in a prostate cancer chemoprevention trial. $\mathrm{J}$ Cancer Educ 1999; 14:88-92.

43 Lerman C, Hughes C, Trock MJ, et al: Genetic testing in families with hereditary nonpolyposis colon cancer. JAMA 1999;281:16181622.

44 National Bioethics Advisory Commission: Research Involving Human Biological Materials: Ethical Issues and Policy Guidance. Rockville, National Bioethics Advisory Commission, 1999.

45 Beskow LM, Burke W, Merz JF, et al: Informed consent for population-based research involving genetics. JAMA 2001;286:2315-2321.

46 Code of Federal Regulations, Title 45 part 46.116. Protection of Human Subjects (Waiver of Informed Consent). Washington, Department of Health and Human Services, 2003.

47 National Commission for the Protection of Human Subjects of Biomedical and Behavioral Research: The Belmont Report: Ethical Principles and Guidelines for the Protection of Human Subjects of Research. Bethesda, Department of Health, Education, and Welfare, 1978, DHEW publication (OS) 78-0012.

- 48 Troug TD, Robinson W, Randolph A, Morris A: Is informed consent always necessary for randomized, controlled trials? N Engl J Med 1999;340:804-807.

49 Merz JF, Caplan AJ: Informed consent for emergency research. JAMA 1995;274:1196.

50 Biros MH, Lewis FJ, Olson CM, Runge JW, Cummin RO, Fost N: Informed consent in emergency research: Consensus statement from the Coalition Conference of Acute Resuscitation and Critical Care Researchers. JAMA 1995;273:1283-1287.

51 Melton L Jr: The threat to medical-records research (comment). N Engl J Med 1997;337: 1466-1470

-52 Jacobsen SJ, Xia Z, Campion ME, et al: Potential effect of authorization bias on medical record research. Mayo Clin Proc 1999;74:330_ 338.

53 National Heart Lung and Blood Institute: Report of the Special Emphasis Panel: Opportunities and Obstacles to Genetic Research in NHLBI Clinical Studies. http://www.nhlbi. nih.gov/meetings/workshops/opporsep.htm.

-54 Earley CL, Strong LC: Certificates of confidentiality: A valuable tool for protecting genetic data. Am J Hum Genet 1995;57:727-731. 